\title{
THE PREVALENCE OF SUBSTANCE USE AMONG FIRST-YEAR STUDENTS AT THE UNIVERSITY OF MOSTAR, BOSNIA AND HERZEGOVINA
}

\author{
Maja Nižić \\ maja.nizic@ffmo.ba \\ University of Mostar, Bosnia and Herzegovina \\ Tanja Penava \\ tanja.penava@gmail.com \\ University of Mostar, Bosnia and Herzegovina \\ Ines Perić \\ ines.peric@ffmo.ba \\ University of Mostar, Bosnia and Herzegovina
}

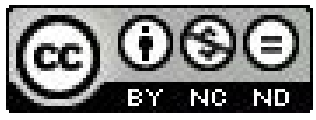

\section{ABSTRACT}

The aim of this paper is to examine the prevalence of substance use among first-year students at the University of Mostar, Bosnia and Herzegovina, and to determine differences with regard to the socio-demographic characteristics of the participants. The study was conducted in June 2012 by teaching assistants at the Department of Social Work, Faculty of Humanities and Social Sciences, University of Mostar, in collaboration with social work students who were previously trained to conduct the research. The study included 420 participants from six faculties. The research is designed to determine which substances are most frequently used among first-year students and to determine whether there are differences in the frequency of alcohol consumption, smoking and drug use among students with regard to their socio-demographic characteristics. The results show that the most frequently used substance among students is alcohol; cigarettes are in second place and marijuana (as the only drug with significant frequency of consumption) in third. Some socio-demographic characteristics have proven to be significant in the frequency of substance use.

Key words: prevalence, substance use, frequency, students.

In contemporary society, many countries are faced with increased alcohol, tobacco and drug use, especially among youth. The World Health Organization estimates that alcohol is the greatest risk factor for premature death or disability in later life. WHO also estimates that as a result of alcohol abuse 2.5 million people die each year, of which 320000 are young people aged 15-29 (World Health Organization [WHO], 2013a) In addition to affecting the health of an individual, alcohol abuse is also the cause of fatal accidents, injuries, child abuse and neglect, violence, murders, suicides, etc. (WHO, 2011). Alcohol abuse is often combined with the use of other psychoactive substances, as well as cigarettes. The European School Survey Project on Alcohol and Other Drugs [ESPAD] (Hibell et al., 2012) is an extremely valuable 
source of information which was carried out in more than 40 countries in Europe. It provides information about alcohol, drugs and tobacco use among 15 and 16 year olds. According to this study, in countries where a large number of students state that they have consumed alcohol in the past 30 days, they also practice episodic heavy drinking (drinking five or more drinks at one time, Binge drinking) more students also state that they have had experience with drugs and inhalants (Hibel et al., 2012).The same research provides information that, as many as $79 \%$ of young people have consumed alcohol in the past 30 days, however, the most disturbing data is about the consumption of five or more drinks at one time (binge drinking). The data shows that, among girls, it increased from $29 \%$ in 1995 to 41 \% in 2007, and in 2011 it slightly dropped to $38 \%$. The average for boys in 2011 was $43 \%$. This percentage is disturbing as it shows that a large number of young people experience heavy episodic drinking and often get drunk (Hibell et al., 2012).

Cigarette consumption among young people is also a major health problem faced by almost every country in the world. According to WHO, the tobacco epidemic is one of the biggest health threats the world has ever faced. It kills nearly 6 million people each year, of which 5 million are consumers or former consumers, and around 600000 are passive smokers. Most smokers live in lower and lower-middle income countries and, in those countries, the number is growing (WHO, 2013b). According to the ESPAD study, about half of the European adolescents in this age group have tried cigarettes at least once in their life, and about $2 \%$ have smoked at least one pack of cigarettes a day in the past 30 days (Hibell et al., 2012). If we take into account that the number of participants is 100000 , this percentage converted to an absolute number is not negligible.

Heroin, cocaine and other drugs kill about 0.2 million people every day, they destroy families and push thousands of people to the edge of existence. Drug abuse is nowadays characterised by the trend concentrated among young people, particularly males living in urban areas. Although drug trafficking is showing signs of stagnation in developed countries, the growth of drug abuse is continuing in developing countries, such as Bosnia and Herzegovina (United Nations Office on Drugs and Crime [UNODC], 2012). According to the 2011 ESPAD study, an average of $21 \%$ of boys and $15 \%$ of girls has tried illicit drugs at least once in their lives, and the most commonly mentioned drug is cannabis. Boys come first in the consumption of most drugs except for the use of tranquilizers that are, on average, consumed more by girls ( $8 \%$ vs. $5 \%$ ) and this tendency is visible in most countries included in the study (Hibell et al., 2012).

The Federation of Bosnia and Herzegovina was included in this study in 2008 (previously only the Serb Republic participated, as a part of Bosnia and Herzegovina). The most common forms of addictive behavior in the Federation of $\mathrm{BiH}$ are smoking, consumption of alcohol, drugs and psychoactive substances, whose usage is associated with environmental factors such as inconsistency of legal mechanisms in limiting access and sale of these substances, relatively low selling prices, especially of cigarettes and alcoholic beverages, advertising and promotion of cigarettes and alcohol despite statutory prohibitions, and especially with the lack of a strategic approach to the permanent financing of prevention and health promotion campaigns (Pilav, 2008). The study also shows that the habit of smoking in early adolescence 
is more widespread among boys. Daily smoking (at least one cigarette a day), is confirmed by a total of $15 \%$ of participants. $31 \%$ of participants state that they have drunk 5 or more drinks at one time, in the last 30 days. At least once in their life, 20 $\%$ of boys and $10 \%$ of girls, have tried marijuana/cannabis. Although marijuana is the most common psychoactive substance, there are other drugs whose usage is widespread among young people. The percentages are smaller, but not negligible (Pilav, 2008). The participants of the ESPAD study in BiH were 15 and 16 year olds (1st grade of high school) in 2008. And thus, the same generation participated in our study, as we conducted our research in 2012 among first-year students (Pilav, 2008). Given that many studies have shown that there is significant prevalence of substance use among the student population (Webb, Ashton, \& Kamali, 1998; Guerra de Andrade, Arruda Vieira Duarte, Pereira Barroso, Guilherme Alberghini \& Garcia de Oliveira, 2012; Bouillet, 2007, cited in Bouillet, 2009) we believe that this study has obtained valuable data that provides insight into the use of substances among students in Mostar. It is, also, very interesting to compare our results with the results of the 2008 ESPAD study and to discover possible trends in substance use (Pilav, 2008).

For many students, the first year of higher education means leaving home, independent living, often self-financing, financial difficulties, adjusting to a different system of learning and teaching, etc. The period of higher education is considered to be one of the most stressful periods in the life of an individual (Hales, 2009, cited in Bland, Melton, Welle \& Bigham, 2012). Sebena, El Ansari, Stock, Orosova, \& Mikolajczyk (2012) conducted a study among freshmen in five European countries and it shows that the symptoms of depression and stress are associated with problematic drinking of students, however it does not show the association with the drinking frequency. Stress in higher education is increasing, and recent studies show that the highest levels of stress are among first year students (Pryon et al., 2010, cited in Pedersen, 2012). In many countries of the world studies are carried out among students and trends of substance use are monitored. For example, in the U.S., Monitoring the Future is an ongoing study of the behavior, attitudes, and values of American secondary school students, college students, and young adults (University of Michigan, 2013). The results of this study for 2011 show that the prevalence of use for nearly all illicit drugs among college students is lower compared with use among their age peers, who do not attend college, but the degree of difference varies considerably by drug (Johnston, O'Malley, Bachman \& Schulenberg, 2012). Amphetamines are the only illicit drugs with higher use among college students than among their non college peers. College students, also, have a higher prevalence of occasions of binge drinking (five or more drinks in a row in the past two weeks) - 36\% vs. $32 \%$. To summarise, non college youth is generally more involved with drugs than college students. In Bosnia and Herzegovina there is virtually no data on the use of psychoactive substances among students, although the Annual Report on Drug Abuse in Bosnia and Herzegovina for 2010 states that, during 2001 and 2006 two studies were conducted among university students (aged 18-25) which show the life prevalence of illicit drugs use (cannabis, ecstasy, inhalants, LSD, cocaine)- 22.5\% in 2001 and 31\% in 2006.

Considering that data on consumption of these substances among students in Bosnia and Herzegovina is quite scarce, with this research we want to draw at- 
tention to this socially significant topic. Students are the section of the population which is expected to be the carrier and advocate of change in our society. To achieve this, they need help to maintain their physical and mental health. Our research can be considered as the beginning of dealing with this problem and, hopefully, it will encourage building of prevention, as well as, intervention programs at the university level.

\section{AIM AND RESEARCH PROBLEMS}

The aim of this research is to examine the prevalence of substance use among first-year students at the University of Mostar, Bosnia and Herzegovina, and to determine differences with regard to socio-demographic characteristics of the participants.

Research problems are defined as follows:

1. To determine which are the most frequently used substances among first-year students at the University of Mostar.

2. To determine whether there are differences in the frequency of alcohol consumption among students with regard to their socio-demographic characteristics.

3. To determine whether there are differences in the frequency of smoking among students with regard to their socio-demographic characteristics.

4. To determine whether there are differences in the frequency of drug use among students with regard to their socio-demographic characteristics.

\section{METHODOLOGY}

Sample. The study included 420 participants, of which 170 were boys and 250 girls. The average age of the participants was 20.088 years.

Measuring instrument. The questionnaire for the needs of this study was designed according to the ESPAD study Questionnaire on substance use, 2011 (Hibell et al., 2012).

Data collection and data processing. The research presented in this paper was conducted at six faculties (Faculty of Humanities and Social Sciences, Faculty of Law, Faculty of Economics, Faculty of Science and Education, Faculty of Civil Engineering and Faculty of Mechanical Engineering and Computing) at the University of Mostar, Bosnia and Herzegovina. Before carrying out the research, the listed faculties were contacted in order to arrange dates for conducting the research. The study was carried out in June 2012 by teaching assistants at the Department of Social Work, Faculty of Humanities and Social Sciences, University of Mostar, in collaboration with social work students who were previously trained in conducting research. The study included 420 participants. Questionnaires were distributed during previously arranged classes. The purpose of the research and the procedure for filling out the questionnaire were explained to the students by the researchers. Filling in the questionnaires lasted, generally, thirty minutes. During data collection, it was possible for the participants of the study to address the researchers for additional clarifications. After the completion of field research, data was entered and processed 
using programme Statistica 7. Firstly, normal distribution of the obtained data was tested but the data was not normally distributed, therefore, we used non parametric statistical procedures. Data was analyzed using descriptive statistics and median test based on chi-square test.

\section{RESULTS AND DISCUSSION}

Frequency of substance use. The most frequently used substance among first-year students at the University of Mostar is alcohol, cigarettes are in the second place and marijuana (as the only drug with significant frequency of consumption) in the third.

According to the study results, $92.38 \%$ of students have consumed alcohol at least once in their life and of that percentage, $46.2 \%$ have consumed alcohol 40 and more times. The research findings show that alcohol is the most commonly used substance among students of the University of Mostar and this figure is in line with international research. For example, Guerra de Andrade et al. (2012) conducted a research on a sample of 12.721 college students throughout Brazil. That study shows that alcohol is the most widely consumed substance, closely followed by tobacco. Passos, Brasil, Santos \& Aquino conducted a research on a sample of 1,054 students of medicine in Rio de Janeiro, Brazil and it also shows that alcohol is the most reported substance in lifetime use (96.4\%) (Passos et al., 2006). Alcohol is also among the most commonly co-administered substances with a variety of drugs (Barrett, Darredeau \& Pihl, 2006).

The results also show that the largest number of participants (34.2\%) have consumed alcohol one to two times in the past 30 days. This generation of young people participated in the 2008 ESPAD study when they were in the first grade of high school. The results of that study show that the prevalence of alcohol consumption during the past 30 days is $48 \%$ in total, of which $59 \%$ are boys and $38 \%$ girls (Pilav, 2008). Over the last 12 months, most of the participants of our study $(19 \%)$ have consumed alcohol 6-9 times.

According to the students' assessment, they have not been drunk during the past 30 days although they state that they have consumed five or more alcoholic drinks in a row. In the past 12 months they have been drunk one to two times, and during the whole life 3 to 5 times. When they drink alcohol they usually consume between 2 and 4 drinks at one time. The study from 2008, when this generation was in the first grade of high school, also showed high prevalence of binge drinking and $31 \%$ of respondents answered that they had had five or more drinks on one occasion, during the last 30 days (Pilav, 2008).

Other studies also show high prevalence of alcohol use among students. Atwoli, Mungla, Ndung' u, Kinoti \& Ogot (2011) report that, among their participants who consume alcohol, $50.4 \%$ admit drinking 5 or more drinks per day, on one or two days in the past month, while $9.2 \%$ have drunk that much on three or more days. The rest of the participants report consumption of less than five drinks on each drinking day. Guerra de Andrade et al. (2012) make even more specific conclusions claiming that while $19.2 \%$ of students who participated in their study use alcohol, $2.6 \%$ of them may be alcohol-dependent. 
The second most frequently abused substance is cigarettes and our participants report that during their lives $75.7 \%$ of them have tried cigarettes and, of that percentage, $35.2 \%$ have smoked 40 and more times. These results are not surprising, given that the results from 2008, with this generation of young people as participants, show that $35 \%$ of respondents answered that they smoked cigarettes, out of which $31 \%$ were boys and $38 \%$ girls (Pilav, 2008). When it is taken into account that studies show that cigarette consumption increases with age (Ljubotina \& Galić, 2002), a higher prevalence of cigarette smoking is to be expected. Research in the USA shows that the prevalence of daily smoking for college students is 7\% (Johnston et al., 2012). Atwoli et al. (2011) also write about prevalence of smoking among students. A total of $203(42.8 \%)$ of the 474 participants who answered the question on smoking admit to having smoked a cigarette at least once in their life (Atwoli et al., 2011). The high prevalence of cigarette smoking among students is also present in the study by Basu, Das, Mitra, Ghosh, Pal \& Bagchi, (2011) where the results show that the practice of smoking cigarettes, in the past 6 months to 1 year, is present among $43.6 \%$ of students and $40 \%$ of participants have smoked for less than 6 months. Half of them (50.9\%) smoke 5-9 cigarettes per day. Research among chinese students has shown a smoking prevalence of 13\% (Abdullah, Fielding \& Hedley, 2002).

As for drug abuse among students in Mostar, frequency of consumption is only significant with regard to marijuana so it is the only substance we singled out. This data is consistent with the 2008 ESPAD study conducted among the generation of young people who are, now, our respondents. Their results show that marijuana is the most common drug among youth (Pilav, 2008). Our study shows that $18.8 \%$ of students have tried marijuana at least once in their life, out of which $12.14 \%$ have consumed it one to two times. Study results of other authors (Atwoli et al., 2011; Barrett et al., 2006; Webb et al., 1998) also show that students mostly consume marijuana while research conducted in China shows that the same percentage of students tried marijuana as well as other illicit drugs.

\section{ALCOHOL CONSUMPTION}

Our study shows significant differences in the frequency of alcohol consumption among students with regard to some of their socio-demographic characteristics. Notably, there are differences with regard to gender. More frequent alcohol consumers are boys and they also lead with regard to drunkenness and consuming more drinks at one time. In accordance with this result are the data from 2008 when the study showed that boys are ahead of girls in all matters concerning the use of alcohol by around $10-15 \%$ (Pilav, 2008). Also, many other worldwide studies confirm that, in student populations, there is a larger number of males who consume alcohol (McCrystal \& Percy, 2011; Guerra de Andrade et al., 2012; Atwoli et al., 2011; Passos et al., 2006; Abdullah et al., 2002).

A significant socio-demographic characteristic is also the place of residence. During the whole life alcohol has been consumed more by students from large cities. This finding is confirmed by the results of the U.S. study Monitoring the Future (Johnston et al., 2012). Their data show that participants from large cities have consumed 
more alcohol in their lifetime, in the past year, in the past 30 days and that $41 \%$ of them have consumed five or more drinks in a row at least once in the two weeks prior the study, compared to $28 \%$ of participants from the country. However, some research suggests that this distinction is increasingly reducing or has disappeared. For example, Maxwell, Tackett-Gibson and James (2006) conducted a study in Texas which suggests that rural areas are not devoid of substance-use problems. Young people in rural areas are engaging in dangerous substance use behavior and, in some cases, doing so to a greater degree than their urban peers. Notably, they are more likely to drink excessively and to drive under the influence.

Frequency of alcohol consumption is, also, connected with the monthly household income. Students who estimate their monthly household income to be more than $2000 \mathrm{KM}$ (students from high income families) have been most frequently drunk during the whole life. These results are also confirmed by foreign studies which suggest that alcohol abuse is about twice as prevalent among students with higher household incomes (Passos et al., 2006; Patrick, Wightman, Schoeni, \& Schulenberg, 2012). Also, the study by Humensky (2010) indicates that higher household income in adolescence is associated with higher rates of binge drinking (among other things) in early adulthood.

Another important characteristic is family relationships. Namely, consumption of alcohol during the past 12 months is most frequent among students who declare their family relationships to be extremely bad, and right behind them are those with mediocre relationships. As for alcohol consumption during life the most frequent consumption is, also, among students with extremely bad and mediocre relationships. Research by Scheer, Lynne, Borden, \& Donnermeyer (2000) shows that good family relationships are a protective factor for the use of all substances and it can be concluded that young people from families with good relationships use less alcohol and other substances. An interesting observation is made by Arbour-Nicitopoulos, Kwan, Lowe, Taman, \& Faulkner (2011) who state that family conflict is associated with females' drinking in both age groups in their study (11 and 13 years) but not males' drinking.

If we look at the frequency of alcohol consumption with regard to the faculty of study, during life alcohol has been most frequently consumed by social work students (from the Faculty of Humanities and Social Sciences), students of civil engineering, law, mechanical engineering and computing. Students from the Faculty of Science and Education consume alcohol least frequently. Data shows that in the past 12 months, students of civil engineering, economics and computing have consumed alcohol more frequently than the others. The frequency of drunkenness in the past 12 months and during the life is the highest among the students of law, mechanical engineering and computing, and the economics students state that they have been drunk least frequently. It is interesting that the students of civil engineering and economics state frequent alcohol consumption but, according to their estimation, they do not get drunk. The most frequent consumers of five or more drinks at one time in the last 30 days are students of social work, law, mechanical engineering and computing. The least frequent binge drinkers are students of languages (from The Faculty of Humanities and Social Sciences) and students of the Faculty of Science and Education. The largest number of drinks in a row is 
consumed by students of mechanical engineering and compared to students of other faculties they drink distinctively more drinks at one time. Students of social work and from the Faculty of Science and Education drink the lowest number of drinks in a row. A study conducted in France (Franca, Dautzenberg, Fallisard \& Reynard, 2010) shows that there is a high prevalence (73\%) of alcohol consumption among students of sociology, and $32 \%$ of them report heavy drinking episodes in the last month which is similar to medical students who have prevalence of heavy episodic drinking of 35\%. Results of the research by Franca et al. (2010) indicates that the academic discipline is associated with overestimation of alcohol and heavy episodic drinking norms and Bouillet (2009) also writes about significant differences when it comes to the field of study. These results coincide with the results of our research while a study conducted in China does not show any differences with regard to the faculty attended by participants (Abdullah et al., 2002).

\section{CIGARETTE CONSUMPTION}

There are also differences in the frequency of smoking among students with regard to some of their socio-demographic characteristics. One of them is gender whereas the data show that more frequent consumers of cigarettes are boys. Many other researches support our findings (Atwoli et al., 2011; Guerra de Andrade et al., 2011; Basu et al., 2011; Abdullah et al., 2002). However, the 2008 ESPAD study has shown that $38 \%$ of girls and $31 \%$ of boys have consumed cigarettes during the life (Pilav, 2008). Similar results are obtained by McCrystal and Percy (2011) who suggest that gender is significantly associated with cigarette smoking and, in their research, males have 34\% lower odds of smoking tobacco in the past year compared to females. There are also studies that do not find statistically significant differences with regard to gender, such as Ljubotina and Galić (2002) and in the U.S. study Monitoring the Future it is stated that since 2001 the differences between genders in terms of cigarette smoking are fading (Johnston et al., 2012).

The results of the study also show that the consumption of cigarettes is more frequent among students who live in large cities. Opposite findings are obtained by Monitoring the Future study which shows that the highest consumption of cigarettes is among the participants from the country and lowest among those from very large cities (daily prevalence rates of 18\% and 9\%) (Johnston et al., 2012). Similarly, a study by Maxwell et al. (2006) shows that daily tobacco consumption is declining in urban areas but remaining constant among rural youths. However, Basu et al. (2011) indicate that no significant difference is present between urban and rural students.

Students whose parents did not finish elementary school have, most frequently, consumed cigarettes in the past 30 days. However, research by Brajša-Žganec, Raboteg-Šarić, \& Glavak, (2002) has shown that there is no difference in parental education between the groups at risk and not at risk of smoking.

No significant differences have been found in the frequency of cigarette consumption with regard to family relationships and the faculty of study. 


\section{DRUG ABUSE}

We have, also, compared the frequency of marijuana use (as the only drug with significant frequency of consumption) among students with regard to their socio-demographic characteristics and we have reached some interesting conclusions.

Notably, in our study there is no statistically significant difference in the consumption of marijuana with regard to gender. Many other researches do not correspond to our results and indicate the existence of differences in consuming marijuana between men and women. For example, according to studies by Guerra de Andrade et al. (2012), McCrystal and Percy (2011), Atwoli et al. (2011), Passos et al. (2006), Webb et al. (1998), men are more frequent marijuana users.

On the other hand, statistically significant difference is found with regard to the faculty of study. Specifically, students of the humanities are the most frequent consumers of marijuana. Unlike Mostar students, in France (Franco et al., 2010) students of sociology are the ones who consume marijuana most frequently, while at The University of Zagreb, Croatia among most frequent consumers are also students of humanities, but together with students of biomedicine and health sciences, engineering and natural sciences (Bouillet, 2009) .

Another important socio-demographic characteristic is the students' place of residence. The results of the study show that marijuana is more consumed by students from large cities. Connection between marijuana consumption and the place of residence also proved to be significant in the study (Johnston et al., 2012). The results of that research show that participants from rural/country areas have the lowest level of use, and those from small towns the next lowest. Medium-sized cities, large cities, and very large cities tend to have higher levels of use with only small variations among them.

Students who estimate their family relations as being extremely bad have consumed marijuana most frequently during their life, during past 12 months and during past 30 days. Other studies (Majdak \& Unković, 2010; Ljubotina \& Galić, 2002; Bamigboye et al., 2007 cited in Bouillet, 2009) also confirm our findings. When young people report that they care about their families and believe that their family cares about them, they are less likely to be involved in any kind of substance use. A positive adolescent-parent relationship is a protective factor in the lives of young people as they are confronted with various life choices, including substance use. The family ethos functions as a safeguard when it comes to adolescents and substance use (Scheer et al., 2000).

Our study does not show statistically significant correlation between the monthly household income of students and the consumpti on of marijuana. Contrary to our findings, Ljubotina and Galić (2002) report that children from average income families consume marijuana less, but, they also warn about the disturbing trend in which the use of marijuana is becoming quite common and accessible to a wide range of children, where material resources become less important and that may be the reason why this socio-demographic characteristic has not proven to be important in our study.

As regards the education of parents, there is significant difference with regard to the education of the mother. Students whose mothers did not complete their education at primary school have consumed marijuana more frequently during their lifetime. As opposed to that, other researches (Passos et al., 2006; Sakoman \& Bra- 
jša-Žganec, 2002; Ljubotina \& Galić, 2002) bring different results. Specifically, according to these studies more frequent consumption is among participants whose parents have higher levels of education.

\section{CONCLUSION}

The results of the study show that, among students of the University of Mostar, the most consumed substance is alcohol, cigarettes are in second place and, in third place, marijuana (the only drug with significant consumption). The differences in the frequency of consumption with regard to certain socio-demographic characteristics of respondents have, also, been determined. The data obtained is consistent with international research.

Given the number of drinks consumed at one time and the frequency of drinking, it is interesting that students estimate that they do not get drunk often. This raises the question of what they mean by drunkenness and how probable it is that they consume five or more drinks at one time and, at the same time, do not get drunk. According to the ESPAD study conducted among this generation in 2008, prevalence of smoking was $35 \%$, while the results of our study show that $75.7 \%$ of students smoke cigarettes (Pilav, 2008). These findings could be interpreted in terms of an increase of cigarette consumption with age which is mentioned by several authors (Atwoli et al., 2011; Ljubotina \& Galić, 2002). Of all the drugs suggested in the questionnaire, marijuana is the most commonly used. There are no significant differences in the consumption of marijuana with regard to the monthly household income which may be the sign of availability of this substance for all strata of society.

However, studies show that adolescents start with substance consumption long before they start their higher education (McCrystal \& Percy, 2011, Atwoli et al., 2011; Hibell et al., 2012), so prevention programs should focus on elementary school students. Along with prevention focused on students it is necessary to make parents aware of the importance of good communication in the family since it has been shown that family relationships can be a protective factor when it comes to substance use.

To conclude, higher education is one of the most stressful periods in person's life. Atwoli et al. (2011) even state the reasons why students take substances: to relax $(62.2 \%)$, to relieve stress $(60.8 \%)$, desire to experiment $(41.9 \%)$, peer pressure $(38.9 \%)$, and to cope with problems (38.9\%). Our results show that students from the University of Mostar also consume substances- alcohol, cigarettes and marijuana, although we did not question the reasons for consumption. However, further studies should be conducted to gain insight into the reasons for substance abuse and to plan necessary prevention and intervention programmes on the basis of those studies in order to help young people and stop them from developing addictions.

\section{REFERENCES}

Abdullah, A. S. M., Fielding, R., Hedley, A. J. (2002). Patterns of Cigarette Smoking, Alcohol Use and Other Substance Use Among Chinese University Students in Hong Kong. The American Journal on Addictions, 11, 235- 246. doi: 10.1080/10550490290088018. 
Arbour-Nicitopoulos, K. P., Kwan, M. Y., Lowe, D., Taman, S., Faulkner, G. E. (2011). Social norms of alcohol, smoking, and marijuana use within a Canadian university setting. The Journal of American College Health, 59 (3), 191-196.

Atwoli, L., Mungla, P. A., Ndung'u, M. N., Kinoti, K. C., Ogot, E. M. (2011). Prevalence of substance use among college students in Eldoret, western Kenya. BMC Psychiatry, 11(1), 34-42. doi: 10.1186/1471244X-11-34.

Barrett, S. P., Darredeau, C., Pihl, R. O. (2006). Prevalence of psychoactive drug use among medical students in Rio de Janeiro. Social Psychiatry E Psychiatric Epidemiology, 41(12), 989-996. doi: 10.1002/ hup.766.

Basu, M., Das, P., Mitra, S., Ghosh, S., Pal, R. Bagchi, S. (2011). Role of family and peers in the initiation and continuation of smoking behavior of future physicians. Journal of Pharmacy and Bioallied Sciences, 3(3), 407-411. doi:10.4103/0975-7406.84452.

Bland, H. W., Melton, B. F., Welle, P., Bigham, L. (2012). Stress Tolerance: New Millennial College Students. College Student Journal, 46 (2), 362-375.

Bouillet, D. (2009). Slobodno vrijeme zagrebačkih studenata: prilika za hedonizam ili samoostvarenje [Students in Zagreb: Free Time - Chance for Hedonism or Self-realisation]. Sociologija i prostor, 46 (3-4), 341-367.

Brajša-Žganec, A., Raboteg-Šarić, Z., Glavak, R. (2002). Gender differences in the relationship between some family characteristics and adolescent substance abuse. Društvena istraživanja, 11(23), 335-352.

Franca, R., Dautzenberg, B., Falissard, B., Reynaud, M. (2010). Peer substance use overestimation among French university students: a cross-sectional survey. BMC Public Health, 10,(169). doi:10.1186/14712458-10-169.

Guerra de Andrade, A., Arruda Vieira Duarte, Pd. C, Pereira Barroso, L., Guilherme Alberghini, D., Garcia de Oliveira, L. (2012). Use of alcohol and other drugs among Brazilian college students: effects of gender and age. Revista Brasileira de Psiquiatria, 34(3), 294-305. doi: 10.1016/j.rbp.2012.02.002.

Hibell, B., Andersson, B., Ahlström, S., Balakieva, O., Bjarnason, T., Kokkevi, A., Morgan, M. (2012). The 2011 ESPAD Report: Alcohol and Other Drug Use Among Students in 30 European Countries. The Swedish Council for Information on Alcohol and Other Drugs, Stockholm, Sweden. Retrieved from: http://www.espad.org/Uploads/ESPAD_reports/2011/The_2011_ESPAD_Report_ FULL_2012_10_29.pdf

Humensky, J. L. (2010). Are adolescents with high socioeconomic status more likely to engage in alcohol and illicit drug. Substance Abuse Treatment, Prevention, and Policy, 5(19). doi: 10.1186/1747597X-5-19.

Johnston, L. D., O’Malley, P. M., Bachman, J. G., Schulenberg, J. E. (2012). Monitoring the Future national survey results on drug use, 1975-2011 (Vol. II): College students and adults ages 19-50. Ann Arbor: Institute for Social Research, The University of Michigan. Retrieved from: http://www.monitoringthefuture.org/pubs/monographs/mtf-vol2_2011.pdf

Ljubotina, D., Galić, J. (2002). Obiteljski odnosi i konzumacija droga na populaciji adolescenata Grada Zagreba [Family Relationships and Drug Use in the Adolescent Population of the City of Zagreb]. Ljetopis socijalnog rada, 9 (2), 207-232.

Maxwell, J. C., Tackett-Gibson, M., James, M. (2006). Substance Use in Urban and Rural Texas School Districts. Drugs: Education, Prevention and Policy, 13 (4), 327-339. doi: 10.1080/09687630600627090.

Majdak, M., Unković, L. (2010). Zlouporaba opojnih droga među adolescentima na području grada Splita [Narcotic Abuse among Adolescents in the City of Split]. Napredak, 151 (1), 45-68.

McCrystal, P., Percy, A. (2011). Patterns of substance use among young people attending colleges of further education in Northern Ireland. Drugs: Education, Prevention and Policy, 18(1), 69-76. doi: 10.3109/09687630903505501.

Passos, S. R. L., do Brasil, P. E. A. A., dos Santos, M. A. B., de Aquino, M. T. C. (2006). Prevalence of psychoactive drug use among medical students in Rio de Janeiro. Social Psychiatry E Psychiatric Epidemiology, 41(12), 989-996. doi:10.1007/s00127-006-0114-7.

Patrick, M. E., Wightman, P., Schoeni, R. F., Schulenberg, J. E. (2012). Socioeconomic Status and Substance Use Among Young Adults: A Comparison Across Constructs and Drugs. Journal of Studies on Alcohol $\mathcal{E}$ Drugs, 73 (5), 772-782.

Pedersen, D. E. (2012). Stress Carry-Over and College Student Health Outcomes. College Student Journal, $46(3), 620-627$. 
Pilav, A. (2008). The European School Survey Project on Alcohol and Other Drugs Federation of Bosnia and Herzegovina Final Report. Federal Ministry of Health. Retrieved from: http://www.uredzadroge.hr/upload/File/Istrazivanja/Espad/The_2011_ESPAD_Report_FULL_2012_06-08.pdf

Sakoman, S., Brajša-Žganec, A., Glavak, R. (2002). Indikatori ranog prepoznavanja visokorizične populacije hrvatske mladeži u odnosi na zlouporabu sredstava ovisnosti. [Indicators of Early Recognition among Croatian Youth at High Risk of Substance Abuse]. Društvena istraživanja, 11 (2-3), 291-310.

Scheer, S. D., Lynne M., Borden, L. M., Donnermeyer, J. F. (2000). The Relationship Between Family Factors and Adolescent Substance Use in Rural, Suburban, and Urban Settings. Journal of Child and Family Studies, 9(1), 105-115. doi: 10.1023/ A:1009467817313.

Sebena, R., El Ansari, W., Stock, C., Orosova, O., Mikolajczyk, R. T. (2012). Are perceived stress, depressive symptoms and religiosity associated with alcohol consumption? Asurvey of freshmen university students across five European countries. Substance Abuse Treatment, Prevention, and Policy, 7(21). doi: 10.1186/1747-597X-7-21.

United Nations Office on Drugs and Crime. (2012). World Drug Report 2012: United Nations publication. Retrieved from: http://www.unodc.org/documents/data-and-analysis/WDR2012/WDR_2012_ web_small.pdf

University of Michigan. (2013). Monitoring the Future. Retrieved from: http:/ / www.monitoringthefuture. org/

European Monitoring Centre for Drugs and Drug Addiction (2010). Godišnji izvještaj o stanju zloupotrebe opojnih droga u Bosni i Hercegovini za 2010.godinu. Retrieved from: http://www.msb.gov.ba/dokumenti/strateski/?id=7437.

Webb, E., Ashton, C.H., Kamali, F. (1998). An update on British medical students' lifestyles. Medical Education, 32(3), 325-331. doi: 10.1046/j.1365-2923.1998.00204.

World Health Organization. (2011). Alkohol. Retrieved from: http://www.who.int/mediacentre/factsheets/fs349/en/

World Health Organization. (2013a). Prevention and young people. Retrieved from: http://www.who. int/substance_abuse/activities/prevention/en/

World Health Organization. (2013b). Tobacco. Retrieved form: http://www.who.int/mediacentre/factsheets/fs339/en/index.html 